\title{
Análise ergonômica dos dispositivos auxiliares de marcha de uma idosa
}

\section{Ergonomic analysis of an elderly woman's gaiting assistive devices}

SOUZA, Mikaela de

Universidade Feevale I mikaela@feevale.br

RENNER, Jacinta Sidegum

Universidade Feevale I jacinta@feevale.br

\begin{abstract}
Resumo
Os idosos têm sofrido cada vez mais mudanças no desempenho das habilidades motoras, associadas ao cotidiano ativo e as mudanças degenerativas. Este estudo de caso tem por objetivo desenvolver uma análise ergonômica dos dispositivos auxiliares durante o processo de marcha de uma idosa. Os dois dispositivos auxiliares analisados cumpriram sua função prática, contudo, como o objetivo da idosa é a descarga de peso, concluiu-se que a muleta Lofstrand foi o melhor dispositivo para uso.

\section{Abstract}

The elderly population have suffered more and more changes in the performance of motor skills, associated with active daily life and degenerative changes. This case study aims to develop an ergonomic analysis of the assistive devices during the gaiting action of an elderly woman. The two assistive devices analyzed achieved their practical function, however, since the objective of the elderly woman is the discharge of weight, it was concluded that the Lofstrand crutch was the best device in terms of ease to use.
\end{abstract}

Palavras-chave: Idoso. Dispositivos auxiliares de marcha. Ergonomia. Design.

Keywords: Elderly. Gaiting assistive devices. Ergonomics. Design. 


\section{INTRODUC̣ÃO}

A sociedade atual está no centro da transição de um processo demográfico que resultará em populações mais velhas em todo o mundo. Esta tendência já pode ser percebida no Brasil, onde a população cresceu em função do aumento da quantidade de adultos e idosos (ONU, 2016). Conforme o Censo do (IBGE) Instituto Brasileiro de Geografia e Estatística de 1991, a porção de pessoas com 60 anos ou mais abrangia 6,3 milhões, ou seja, aproximadamente, 4,19\% da população na época. Já no Censo de 2010, encontra-se 20,6 milhões, representando 10,79\% da população. Em decorrência da melhoria na qualidade de vida e diminuição da mortalidade, a expectativa é que em 2025, esses dados alcancem 32 milhões de idosos no Brasil (IBGE, 2010).

Embora o envelhecimento não seja um processo funcional unitário, ele é percebido de formas diferentes em cada cultura e costuma ser associado a uma imagem positiva onde indivíduo que envelhece acumula experiências e qualidades. "O idoso deseja aprender, se envolver e participar cada vez mais ativamente desse processo de mudanças em que vivemos diariamente" (FERREIRA et al., 2008, p. 106). Observa-se que a partir desta perspectiva, os idosos estão mais ativos na sociedade, contribuindo com a vida social e política da comunidade que estão inseridos.

A medida que os anos passam, encontra-se nos músculos e ossos os maiores e mais visíveis problemas. Entre as alterações percebidas está a diminuição dos músculos, o aumento de gordura corporal e a insuficiência musculoesqueletal, causada pela capacidade reduzida de produzir as proteínas necessárias que se acelera após os 50 anos. Por volta dos 65 ou 70 anos, aproximadamente $1 / 3$ da força muscular se perdeu, sendo resultado de uma combinação de menos fibras musculares, um tamanho menor de cada fibra e a capacidade reduzida de cada fibra funcionar da maneira correta (NULAND, 2007, p. 41).

O envelhecimento se manifesta em todos os domínios da vida, iniciando-se pelas células, passando para os tecidos e órgãos, terminando no emocional. Embora o físico e a mente envelheçam juntos, o processo não se efetiva no mesmo ritmo. Na grande maioria, o físico se evidencia, pela perda da massa muscular, ao passo que a mente, torna-se mais apta, principalmente no controle das emoções (GARCIA, 2001, p. 25).

Os idosos possuem menos massa muscular do que os indivíduos jovens e com a diminuição do metabolismo de energia das fibras musculares, tem-se como resultado a atrofia relacionada à idade (ARKING, 2008). Essa perspectiva, 
associada ao cotidiano cada vez mais ativo e as mudanças degenerativas, repercute nas condições funcionais e no desempenho das habilidades motoras.

A consequência de tais disfunções causa mudança no padrão da marcha. A marcha normal depende da mobilidade das articulações e da ação muscular apropriada para produzir a força e do condicionamento físico. Durante a fase de locomoção, o centro de gravidade do corpo se localiza fora da base de sustentação, passando próximo a margem interna do pé. Neste processo, surgem momentos de fragilidade, facilitando as quedas e as lesões graves delas decorrentes, sendo assim, a marcha é uma atividade altamente instável. (PICKLES et al., 1998; RAMOS, 2005).

O risco de queda em idosos é associado a perda da força muscular e a um maior consumo energético na marcha, pois uma marcha lenta exige um aumento no consumo de energia do corpo. Neste caso, o aumento pode ser de 33\% maior em idosos do que em adultos jovens (MARQUES et al., 2013). Spidurso (2005), comenta que as pessoas idosas têm uma marcha lenta, porém, sua lentidão não ocorre porque não conseguem caminhar rápido, mas sim, porque preferem caminhar em um ritmo mais devagar. A marcha lenta, facilita a adaptação dos idosos aos níveis de controle locomotor: passos e padrões de apoio, controle da postura e equilíbrio e adaptação as mudanças do ambiente (SPIDURSO, 2005, p. 187).

Como forma de auxílio no processo de marcha das pessoas idosas, existem os dispositivos auxiliares de marcha, definidos como itens, peças ou sistemas, destinados a aumentar, manter ou melhorar as capacidades funcionais do indivíduo. Existem três categorias principais: as bengalas, muletas e andadores (PICKLES, 1998, p. 360). Uma de suas funções principais está em eliminar ou transferir a carga, parcial ou completa, sobre um membro inferior, para o membro superior, através da pressão exercida no dispositivo auxiliar. No caso dos idosos, podem ser prescritos para problemas de equilíbrio, fraqueza, instabilidade articular, fadiga, dor e carga esquelética excessiva (CHAMLIAN, 2010, p. 365).

Chamlian (2010) ainda comenta que os dispositivos auxiliares de marcha podem ser extremamente úteis para a qualidade de vida dos indivíduos, quando corretamente indicados, prescritos e utilizados. É importante que o paciente passe por um processo de reabilitação a fim de treinar o uso correto do dispositivo, pois não é raro, encontrar pessoas que utilizam por indicação própria ou de familiares, alguns auxiliares ou até mesmo adaptações. Neste processo, também é preciso desmistificar o preconceito que ainda existe em torno dos auxiliares de marcha (de que são sinônimos de impotência), enquanto, ao contrário, se constituem como potencializadores da função.

A ergonomia surge neste processo como uma compreensão fundamental nas interações entre os seres humanos e outros componentes de um sistema, 
com o objetivo de otimizar o bem-estar das pessoas e o desempenho dos sistemas. Neste caso, a natureza da prática ergonômica se dará como atividade de diagnóstico e intervenção, onde em primeiro lugar, identificaremos a natureza dos problemas existentes e então aplicaremos as regras de ação possibilitando corrigir a situação (FALZON, 2007). Através desse contexto, o objetivo desse estudo foi desenvolver uma análise ergonômica de dispositivos auxiliares durante o processo de marcha de uma idosa no interior do Rio Grande do Sul.

\section{METODOLOGIA}

Esta pesquisa se caracteriza como um estudo de caso, utilizando coleta de dados detalhada. Segundo Gil (2009), estudo de caso é um delineamento adequado para a investigação profunda de um fenômeno contemporâneo dentro de seu contexto real e proporciona o tratamento dos fenômenos de um ponto de vista sistêmico.

Este estudo de caso se iniciou com o contato entre pesquisadora e avaliada, onde a idosa foi informada sobre os objetivos do estudo e concordou em participar. Em seguida marcou-se um dia e horário específicos para a realização da coleta de dados.

No dia marcado, a coleta de dados se iniciou com uma entrevista aberta, constituindo a principal fonte de evidência para extrair os fatos. Ocorreu ainda a construção de uma base de dados empregando múltiplas fontes de evidência, como anotações e gravação do áudio da entrevista através de gravador.

Sob paradigma etnográfico, utilizou-se de recursos audiovisuais para registrar takes de caminhadas e locomoção da entrevistada e a sua interação com o dispositivo auxiliar de marcha. Ainda se utilizou de um dispositivo móvel com câmera fotográfica para registros complementares, tornando a análise e discussão de dados fidedigna. Segundo Gil (2009), a pesquisa etnográfica se caracteriza pelo estudo de pessoas em seu ambiente mediante a utilização de procedimentos como entrevistas em profundidade e observação do entrevistador. Ainda é utilizada para a descrição de comportamentos, baseada em informações coletadas mediante trabalho de campo.

Durante a coleta de dados, pode-se aplicar a Planilha RULA de Acompanhamento. Stanton (2005) afirma que o Rapid Upper Limb Assessment, mais conhecido como método RULA, foi desenvolvido por McAtamney e Corlett em 1993 e avalia postura, força e movimentos usando observações adotadas pelos membros superiores, pescoço, costas e braços, antebraços e punho.

A partir da visão do design, utilizou-se de metodologias de Löbach (2001) e Baxter (2011). Por se tratar de um processo criativo e de solução de 
problemas incorporando as características que satisfaçam as necessidades humanas, quanto mais ampla for a abordagem do problema, mais aumentam as combinações entre variáveis e há uma maior probabilidade de se chegar a soluções (LOBACH, 2001, p. 140).

\section{RESULTADOS}

\subsection{Identificação do Sujeito}

O sujeito deste caso é uma idosa com 85 anos de idade, estatura de $1,60 \mathrm{~m}$ e massa corporal de $98 \mathrm{~kg}$ (figura 1). Natural da região serrana do Rio Grande do Sul, atuou na maior parte de sua vida trabalhando na pecuária, com rebanho leiteiro e na agricultura, com o plantio de batatas. Casou-se aos 19 anos, teve 7 filhos e ao longo de sua vida sempre teve a arte do canto como lazer, onde participou de diversos Corais da região e gravou 3 LPs e 5 CDs. É muito religiosa, sendo uma figura importante na Paróquia da cidade como zeladora da capelinha e integrante da Ordem Franciscana. Descendente de família italiana, tem o dialeto vêneto como sua segunda língua.

Atualmente, a entrevistada faz tratamento fisioterapêutico 2 vezes na semana, na segunda-feira e sexta-feira. Nas segundas e quartas faz Pilates, um método de exercício para fortalecimento muscular e alongamento. Ela relata que iniciou a utilização da bengala quando tinha 82 anos por indicação do médico ortopedista, pois foi diagnosticada com artrose no joelho. $O$ médico indicou que ela iniciasse a utilização e uma de suas noras foi até uma loja na capital e fez a aquisição sem receituário, de uma bengala ajustável de alumínio, dando de presenta à idosa no seu aniversário no mês de março. Ela utilizou este dispositivo até abril de 2016.

Neste mesmo mês trocou a bengala simples por uma muleta ajustável com apoio de antebraço chamada de Lofstrand. O motivo da troca se deu pois relatava dores no ombro e no antebraço que começou a sentir em torno de 3 meses antes desta data. Assim um dos filhos indicou que ela trocasse, mas não deu ouvidos. Relatando as mesmas dores ao fisioterapeuta, o profissional indicou que ela fizesse a troca pois a anterior castigava seu braço. Ela ainda relata que as dores eram somente quando utilizava a bengala simples e o lado que utiliza o dispositivo era o direito, porque sempre trabalhou com esta mão para todas as tarefas. Sobre a adaptação a esta nova muleta, ela relata que não teve estranhamento.

Em relação a locomoção, a idosa comenta que tem dificuldade para caminhar por causa da artrose no joelho e dores nas costas, e comenta que ao se locomover, o corpo dela balança. Quando questionada sobre a sua 
locomoção na rua, ela relata que onde tem calçada ou asfalto, consegue andar normalmente, mas no paralelepípedo, têm buracos e a bengala desce.

A utilização da bengala pela idosa se dá toda vez que ela sai de casa, o que acontece diariamente. Segundo ela, sem a bengala não faria nenhum passo, pois Ihe protege e dá segurança, sem a bengala não conseguiria andar e cairia seguido. Ela relata que sempre indica a utilização de bengala para os outros idosos que caminham um pouco tortos. Quando questionada sobre alguma mudança no dispositivo ela comenta que não mudaria nada e que não tem nada para mudar. Em relação a quedas, desde que começou a utilizar nunca caiu, mas sem a bengala caiu uma vez.

Ela relata que não teve intervenções cirúrgicas nas regiões do joelho e costas, mas o médico ortopedista que cuida do seu tratamento atual pretende fazer uma intervenção no joelho. Ainda enfatizou que não colocará prótese pois o tratamento (fisioterapia, pilates, medicação e gelo no joelho) ao invés de melhorar, está piorando.

Figura 1 - Idosa.

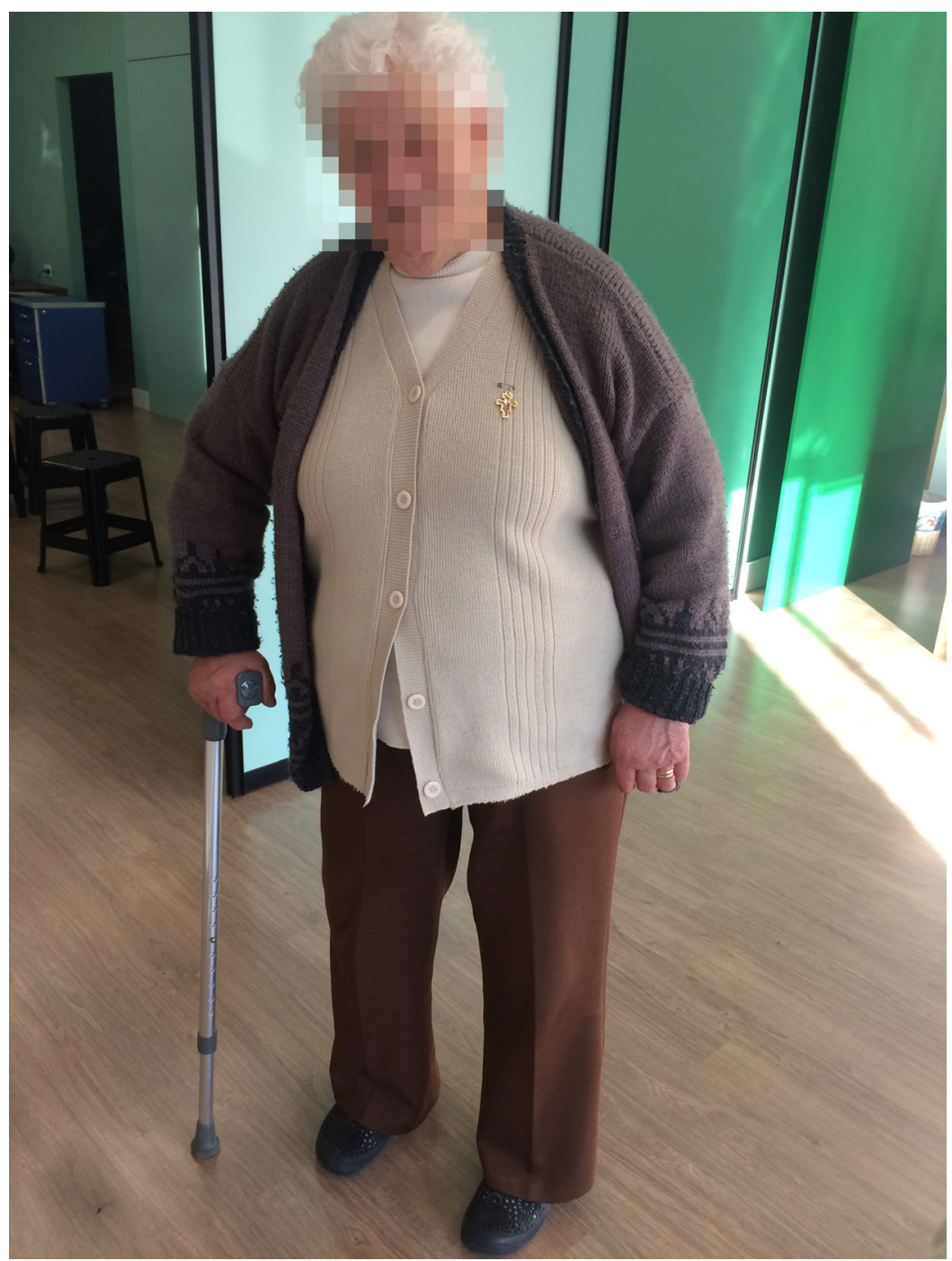

Fonte: Autores (2016). 


\subsection{Dispositivos Auxiliares}

A bengala comum (Figura 2) tem como função auxiliar no equilíbrio, diminuir a dor, poupar o membro lesado, compensar a força e adicionar informação sensorial. É capaz de diminuir de 20 a 25\% do peso descarregado no membro e seu uso é na grande maioria das vezes na mão contralateral do membro afetado. Quando utilizado na mão ipsilateral, pode promover inclinação do tronco, braço de alavanca menos favorável, menor base de sustentação e comprometer a dissociação de cinturas. Ainda pode causar estresse no punho (CHAMLIAN, 2010, p. 365). Esta bengala, utilizada pela idosa, tinha as seguintes medidas: $88 \mathrm{~cm}$ de altura, $12 \mathrm{~cm}$ da pega, $29 \mathrm{~cm}$ estrutura ajustável.

Figura 2 - Bengala Comum.

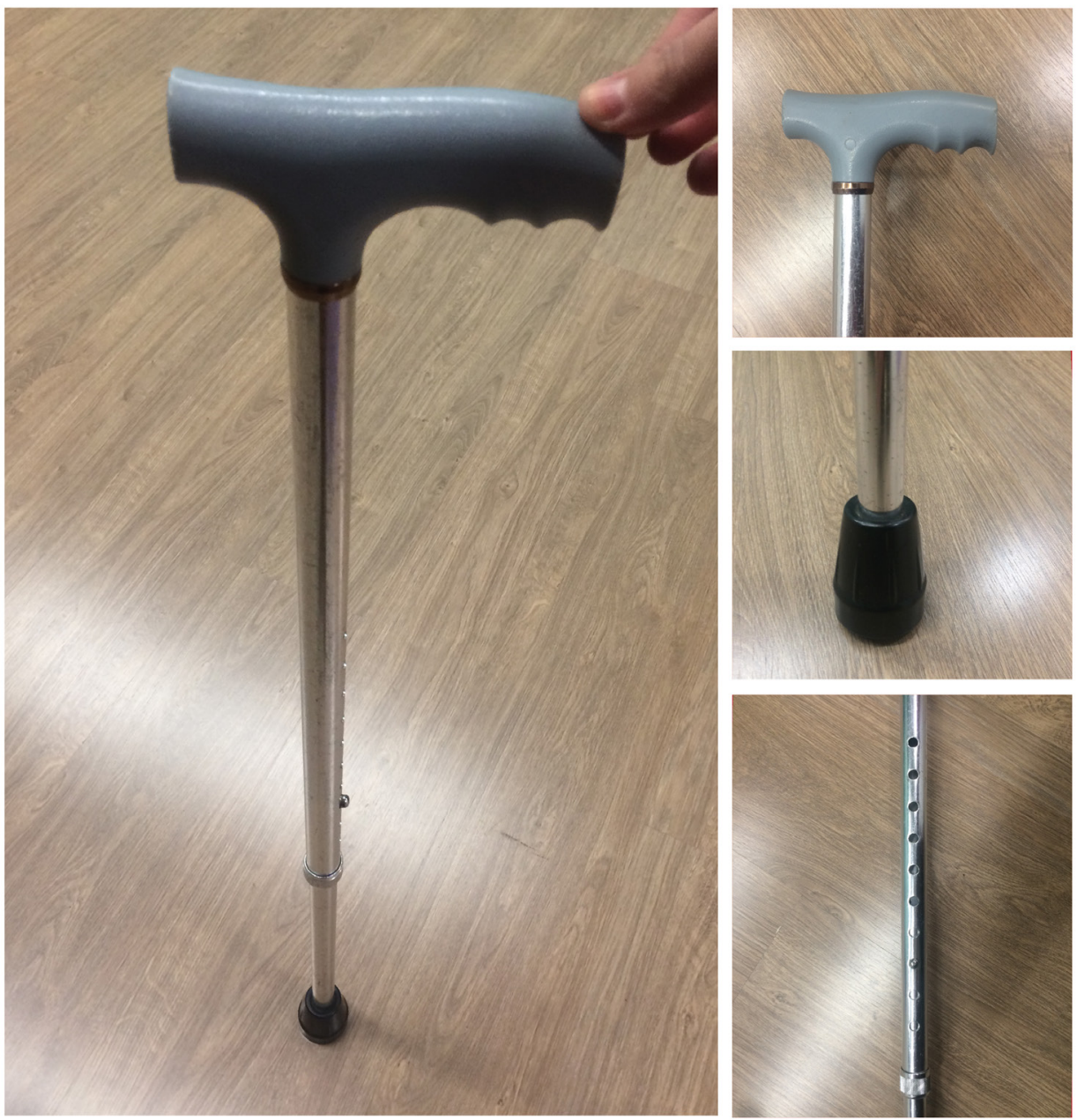

Fonte: Autores (2016)

A muleta Lofstrand (Figura 3), estilo com uma braçadeira ao nível do antebraço, tem como benefício maior estabilidade e é utilizada para descarga de peso e propulsão. As muletas de modo geral podem reduzir de 50 a 100\% do peso de um membro, dependendo da sua forma de utilização. Normalmente são utilizadas em pares e exigem um bom equilíbrio de tronco, membros superiores fortes e boa coordenação, além de darem liberdade as mãos (CHAMLIAN, 2010, p. 366). 
Esta muleta, utilizada pela idosa, tinha as seguintes medidas: 1,30 m de altura, $33 \mathrm{~cm}$ de amparo ao braço, $18 \mathrm{~cm}$ estrutura ajustável e 1 metro da pega ao chão. Os materiais são alumínio na parte metálica; na braçadeira e punho é utilizado polipropileno e na ponteira, borracha.

Figura 3 - Muleta Lofstrand.
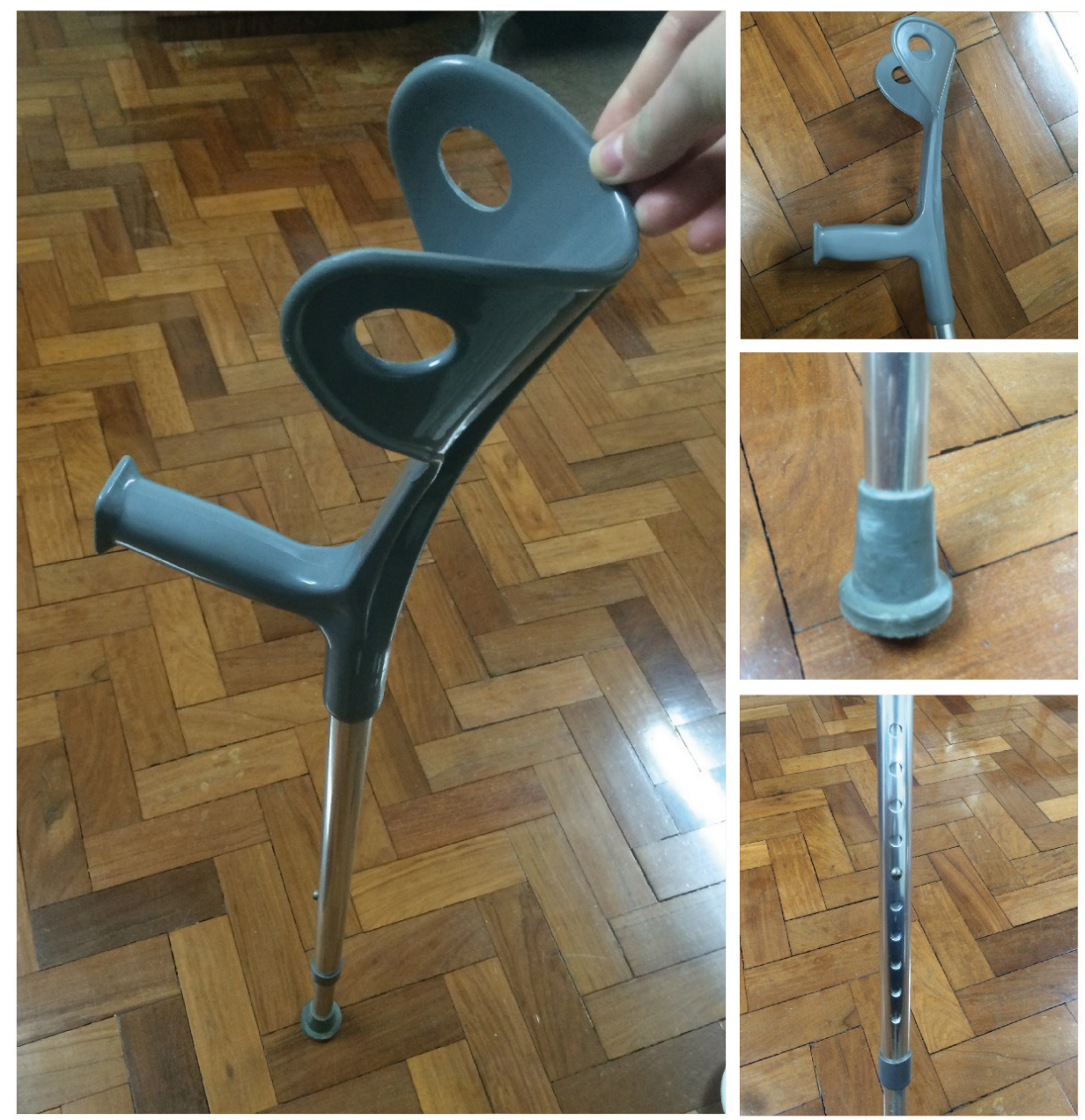

Fonte: Autores (2016).

\section{ANÁLISE E DISCUSSÃO}

Os dois dispositivos auxiliares, tanto a bengala quanto a muleta, estavam cumprindo sua função prática ( $L O ̈ B A C H, 2001)$ satisfazendo a necessidade fisiológica do usuário, amparando o corpo da idosa e auxiliando durante o processo de marcha. Nesse sentido, vale ressaltar que o objetivo da idosa é a descarga do peso para o membro superior, visto que antes era feito nos membros inferiores afetando a sua artrose no joelho. Neste caso, o melhor dispositivo para uso é a muleta Lofstrand, que pode reduzir de 50 a 100\% o peso de um membro. Chamlian (2010) comenta que não é raro, na prática clínica, encontrar pacientes utilizando dispositivos inadequados e adaptados por indicação própria. Cabe ao médico orientar o dispositivo adequado, treinar o uso correto e apresentar os benefícios quando bem utilizados (CHAMLIAN, 2010, p. 368). 
Em segundo momento, como os dispositivos apresentavam diferentes alturas, optou-se por analisar a adequação da altura do objeto em relação a altura da idosa. Para isso utilizou-se as os dimensionamentos humanos para espaços interiores, de Panero e Zelnik (2002). Conforme os autores, os números da antropometria funcional de mulheres idosas em pé são:

a) Altura do punho fechado até o chão, em posição anatômica (braço ao longo do tronco): média de 70,1 cm;

b) Altura do punho fechado ao chão, com obstrução a $35 \mathrm{~cm}$ : média de $82,4 \mathrm{~cm}$.

Estes dados, em comparação com a bengala utilizada pela idosa difere em $6 \mathrm{~cm}$ e em relação a muleta, $18 \mathrm{~cm}$, seguindo como parâmetro a letra $b$, partindo da altura do punho até o chão. Estas diferenças se tornam preocupantes quando há um relato de fadiga no antebraço e ombro. O uso dos dispositivos tem como objetivo reduzir a carga nos membros inferiores durante a marcha, o que pode aliviar a dor articular destes membros, mas podem causar desequilíbrio e dores nos membros superiores quando apoiados de uma forma incorreta (FERREIRA et al., 2008).

Como sugestão de intervenção, a melhor forma é adequar os dispositivos à altura da idosa, seguindo os padrões antropométricos sugeridos pelos autores. Esta mudança foi levada até ela e a altura foi adequada e testada. No início, ela teve dificuldades para se adaptar, mas após dar alguns passos percebeu que o braço em que utilizava a muleta Lofstrand sofria menos para locomover a bengala e acompanhar o passo.

Uma outra questão a ser analisada no relato da idosa é que dentro dos padrões de deambulação, os dispositivos auxiliares de marcha são utilizados na mão contralateral ao membro inferior lesado e avança junto com ele, sendo a forma mais indicada de uso, conforme Chamlian (2010). Neste caso, observouse durante a entrevista e as gravações de vídeo com a idosa de que ela é destra e utiliza os dispositivos na mão direita.

Esta condição certamente maximiza o quadro de dor sofrido por ela, por conta da utilização dos dispositivos auxiliares de marcha no braço onde tem mais força. Quando conversamos com a idosa a respeito da utilização da muleta na mão direita, ela nos relatou que tentou utilizar na outra mão, mas que não se sentia segura porque sempre teve o braço direito como membro de força. Neste caso, pouco se teve como intervir em função da idosa já relatar um quadro de adaptação em relação ao dispositivo que utilizava.

Outro ponto muito importante para a saúde relatado pela idosa é que não houve quedas após o início da utilização dos dispositivos. Segundo Ramos (2005), cerca de 30\% dos idosos caem pelo menos uma vez por ano, e 10\% cairão duas ou mais vezes no mesmo período. Logo, é preciso garantir estratégias para a prevenção de quedas e fraturas, entre elas garantir a resistência óssea, 
evitar a ocorrência de quedas eliminando as barreiras que os idosos convivem diariamente e utilizar de dispositivos que auxiliem na deambulação.

Quando analisada a Planilha Rula da utilização do dispositivo muleta Lofstrand pela idosa, obteve-se resultado 03, que significa investigar depois. Apenas este dispositivo foi avaliado pois é o que a idosa utiliza no momento. Kauffman (2001, p. 299) comenta que o posicionamento ou suporte para aliviar a tensão de uma área pode ajudar a reduzir a dor. Neste caso, foi apresentado o resultado para a idosa e proposta as melhorias necessárias para que a marcha e a qualidade de vida não fossem afetadas pelo dispositivo, pois os auxiliares de marcha devem servir de apoio para evitar lesões adicionais e não ser o motivo de novas patologias. É importante que a postura, a força aplicada e os movimentos estejam de acordo para o alívio das tensões.

\section{CONSIDERAC̣̃̃ES}

Considerando o cenário pesquisado, este estudo evidenciou a utilização de dois dispositivos auxiliares de marcha por uma idosa. Assim, pode-se pensar em duas maneiras de perceber o olhar da ergonomia dentro dos projetos de design: o olhar do usuário e das suas intervenções em relação ao dispositivo e do designer como criador e com condições de identificar e solucionar problemas.

Nestas interações, surgem possibilidade de trocas de informações e melhorias na qualidade de vida dos usuários. Estas melhorias mesmo que pequenas, são extremamente significativas para os idosos que carecem de informações relacionadas aos dispositivos que podem auxiliar na marcha.

Por isso esse trabalho mesmo que com uma pequena amostra tem a intenção de aprofundar o olhar do designer e fazer com que ele cresça junto da interação com o usuário, para tornar os projetos de produtos, ainda mais entrelaçados. 


\section{REFERÊNCIAS}

ARKING, Robert. Biologia do envelhecimento: observações e princípios. Ribeirão Preto, SP: FUNPEC-Editora, 2008.

BAXTER, Mike. Projeto de produto: guia prático para o design de novos produtos. São Paulo: Blucher, 2011.

CHAMLIAN, Therezinha Rosane. Medicina física e reabilitação. Rio de Janeiro: Guanabara Koogan, 2010.

FALZON, Pierre. Ergonomia. São Paulo: Blucher, 2007.

FERREIRA, Anderson J.; FRAQUELLI, Ângela A.; SCHWANKE, Carla H. A.; WEHEMEYER, Cláudia de Oliveira T.; MACHADO, Letícia R.; TERRA, Newton L.; SCHNEIDER, Rodolfo H.; LINDÔSO, Zayanna (org.). Inclusão digital de idosos: a descoberta de um novo mundo. Porto Alegre: EDIPUCRS, 2008.

GARCIA, Heliéte Dominguez. A terceira idade e a internet: uma questão para o novo milênio. 2001. 172 f. Tese (Mestrado em Ciência da Informação) Faculdade de Filosofia e Ciências da Universidade Estadual Paulista, Marília, 2001.

GIL, Antônio Carlos. Estudo de caso. São Paulo: Atlas, 2009.

IBGE. Censo demográfico 2010. 2010. Disponível em: http://www.censo2010. ibge.gov.br/sinopse/index.php?uf=00\&dados=1. Acesso em: 18 maio 2016.

KAUFFMAN, Timothy L. Manual da reabilitação geriátrica. Rio de Janeiro: Editora Guanabara Koogan, 2001.

LÖBACH, Bernd. Design industrial: bases para a configuração dos produtos industriais. São Paulo: Blucher, 2001.

MARQUES, Nise Ribeiro; LAROCHE, D. P.; HALLAL, Camilla Zamfolini; CROZARA, Luciano Fernandes; MORCELLI, Mary Hellen; KARUKA, Aline Harumi; GONCCALVES, Mauro. Association between energy cost of walking, muscle activation, and biomechanical parameters in older female fallers and non-fallers. Clinical Biomechanics, Oxford, GB, v. 28, n. 3, p. 330-336, 2013.

NULAND, Sherwin B. A arte de envelhecer. Rio de Janeiro: Objetiva, 2007.

ONU - Organização das Nações Unidas. Pessoas idosas. Disponível em: https://nacoesunidas.org/acao/pessoas-idosas/. Acesso em: 18 maio 2016.

PANERO, Julius; ZELNIK, Martin. Dimensionamento humano para espaços interiores. Barcelona: Editorial Gustavo Gili, 2002.

PICKLES, Barrie; COMPTON, Ann; JANET, COTT, Cheryl; SIMPSON, Janet M.; VANDERVOORT, Anthony. Fisioterapia na terceira idade. São Paulo: Editora Livraria Santos, 1998.

RAMOS, Luiz Roberto. Guia de geriatria e gerontologia. Barueri, SP: Manole, 2005. 
SPIDURSO, Waneen Wyrick. Dimensões físicas do envelhecimento. Barueri, SP: Manole, 2005.

STANTON, N. Handbook of human factors and ergonomics methods. Boca Raton, FL: CRC Press, 2005.

Data de submissão: 2018-01-02

Data de aceite: 2019-05-21 